\title{
As licenças Creative Commons e suas potencialidades para a circulação do jornalismo digital
}

\author{
Marcelo de Franceschi Santos \\ Universidade Federal de Santa Maria - mfjornalss@gmail.com \\ Jornalista formado na UFSM em 2011
}

\begin{abstract}
Resumo
Descrever o desenvolvimento das licenças Creative Commons e algumas de suas utilizações na circulação do jornalismo digital é o objetivo deste trabalho. Para isso, é feita uma delimitação dos direitos autorais compreendidos pela legislação brasileira, junto a um breve histórico do surgimento das leis de copyright. Depois, menciona os movimentos de contestação dos abusos promovidos pelo aumento da duração e da abrangência dos direitos autorais. Dentre os movimentos, destacam-se a cultura livre (LESSIG, 2005), o copyleft (STALLMAN, 2002), e o Creative Commons (VERCELLI, 2009). Por fim, são citados exemplos da utilização das licenças livres por sites jornalísticos, apontando para uma relativização dos direitos autorais do jornalismo digital.
\end{abstract}

Palavras-chave

Jornalismo Digital, Creative Commons, Circulação da Informação.

\begin{abstract} journalism.

\section{Keywords}

Digital Journalism, Creative Commons, Information Flow.
\end{abstract}

Describe the development of Creative Commons licenses and some of its uses in the circulation of digital journalism is the objective of this work. To do this, it is done a delimitation of copyright understood by the brazilian legislation, along with a brief history about the emergence of copyright law. After, it mention the movements that protest over the abuses promoted by increasing the duration and scope of copyright. Among the movements, it is highlight the free culture (Lessig, 2005), copyleft (Stallman, 2002), and Creative Commons (VERCELLI, 2009). Finally, examples are cited of the use of free licenses for news sites, pointing to a relativization of the copyrights of digital

Artigo recebido em $07 / 03 / 2012$

Aprovado em 05/04/2012 
Estudos em Jornalismo e Mídia - Vol. 9 N I - Janeiro a Junho de 2012 compartilhamento de arquivos através da internet provoca questionamentos sobre a validade, as possibilidades e as consequências dessa prática em todo o mundo. Principalmente a partir de 1999, com o uso de softwares de rede P2Pi, foi posto em xeque o valor das obras intelectuais e artísticas que passaram a ser usufruídas gratuitamente pelos usuários. A reprodução - não apenas a produção - de um produto cultural derivado do intelecto nunca foi tão facilitada com a tecnologia, o que tem gerado processos judiciais efetuados pelos detentores dos direitos autorais das obras compartilhadas nas redes.

Tais complicações jurídicas se devem basicamente à inadequação da lei ao avanço tecnológico. A legislação brasileira dos direitos autorais, por exemplo, data de 19 de fevereiro de 1998, anterior aos serviços de trocas de arquivos. Juntamente com o copyright estadunidense, a Lei dos Direitos Autorais é tida por especialistas como uma das mais restritivas do mundo. A irrupção da internet e da tecnologia digital possibilita que os usuários façam circular entre si tanto obras próprias quanto obras alheias por preços mínimos ou nulos, sem a permissão dos autores exigida pela lei.

Os direitos autorais são um ramo do Direito que fazem parte de uma classificação maior, chamada pela doutrina internacional de Propriedade Intelectual (PI). Nessa classificação, o ramo dos direitos de propriedade industrial junta-se aos direitos autorais, conforme Castro (2001). Chama-se de propriedade intelectual, segundo Abrão (2001, p. 33), "tudo aquilo que, fruto do esforço intelectual, individual ou coletivo, possa ser reproduzido e comercializado como mercadoria especial, sobre a qual exercem-se direitos de propriedade intelectual". São produtos derivados do intelecto, que nos acompanham todos os dias: livros, jornais, softwares, garrafas de refrigerante, etc. Tudo regulado pelos direitos de propriedade industrial, ou pelos direitos autorais.

Os direitos de propriedade industrial são explicados por Castro como sendo relacionados "com marcas identificativas de empresa, marcas de serviços, nome comercial, bem como se relacionam com patentes de invenções e modelos de utilidade, desenhos ou modelos industriais" (CASTRO, 2001, p. 4). São comumente conhecidos como "marcas e 
Estudos em Jornalismo e Mídia - Vol. 9 N I - Janeiro a Junho de 2012

patentes". Para que um bem seja contemplado pela Lei de Propriedade Industrial, exige-se o registro da produção no órgão regulatório de cada país - no Brasil, isso é feito pelo Instituto Nacional de Propriedade Industrial ${ }^{\mathrm{ii}}$ desde 11 de dezembro de 1970.

Já no caso da Lei dos Direitos Autorais (LDA), qualquer manifestação física ou digital - o que inclui programas de computador - do pensamento não necessita de registro, sendo um ato facultativo, conforme o artigo 18 da lei 9.610/1998: "A proteção aos direitos de que se trata esta lei independe de registro". Ressalta-se que a proteção da lei recai sobre a exteriorização, a forma da expressão fixada independente do material, e não sua ideia original. "As ideias são de uso comum e, por isso, não podem ser aprisionadas pelo titular dos direitos autorais" (PARANAGUA; BRANCO, 2009, p. 31). Por exemplo, é coberta uma única notícia de um determinado fato, e não o fato em si, do qual podem ser feitas outras notícias. "Já no caso dos bens protegidos por propriedade industrial, o que se protege inicialmente é a ideia, consubstanciada em um pedido de registro (de marca) ou de patente (de invenção ou de modelo de utilidade)" (PARANAGUA; BRANCO, 2009, p. 32).

Os direitos autorais estão relacionados a obras intelectuais. Por sua vez, os direitos autorais dividem-se em direitos morais e direitos patrimoniais. Os direitos morais dizem respeito aos direitos de personalidade, dos quais se destacam à honra; ao nome; e à imagem. Tem como características serem intransmissíveis, inalienáveis, irrenunciáveis, inexpropriáveis e imprescindíveis (ABRÃO, 2001). Ninguém pode vender o seu nome para outra pessoa, nem ter sua autoria retirada, ou renunciar a autoria de uma obra. $\mathrm{O}$ nome do autor permite a responsabilização do indivíduo em meio à sociedade (CASTRO, 2001).

Os direitos patrimoniais, por outro lado, são passíveis de venda para exploração comercial, seja pelo autor ou por pessoa autorizada pelo autor. Castro (2001, p. 7) compara brevemente as duas divisões de direitos: "o direito patrimonial de autor tem características diferentes daquelas relativas ao direito moral de autor, a saber: alienável; penhorável; temporário; prescritível". São direitos alienáveis através de um contrato de cessão, por um determinado tempo. Uma série de direitos patrimoniais é elencada pelo artigo 29 da LDA, dentre ela os de reprodução, edição, adaptação, tradução e distribuição da obra cessionada. 
Estudos em Jornalismo e Mídia - Vol. 9 N I - Janeiro a Junho de 2012

A exploração desses direitos gera ganhos econômicos ao autor, financeiramente chamados de royalties.

Um autor pode lucrar com seus direitos patrimoniais, ao vendê-los para difusores de obras intelectuais. Uma banda cede os direitos patrimoniais de um disco para a exploração por uma gravadora; um jornalista cede os direitos patrimoniais de seus escritos para uma empresa através de um contrato, como esclarece o artigo 36 da lei 9610: "O direito de utilização econômica dos escritos publicados pela imprensa, diária ou periódica, com exceção dos assinados ou que apresentem sinal de reserva, pertence ao editor, salvo convenção em contrário". A utilização econômica se dá através do direito patrimonial de reprodução. No jornalismo, por este ser considerado um trabalho intelectual conforme o parágrafo $1^{\mathrm{o}}$ do artigo 302 da Consolidação das Leis do Trabalho ${ }^{\mathrm{iii}}$, é através do contrato que a empresa adquire o direito de reprodução da obra, ou o direito de cópia.

Entretanto, não há na legislação vigente, tanto nacional quanto internacional, definições legais sobre a reprodução de obras intelectuais digitalizadas. A atual legislação considera o meio digital "nada mais que um novo canal de veiculação de obras intelectuais ao qual se aplicam todas as regras de direitos autorais incidentes sobre as outras mídias (impressa, eletrônica, radiodifundida)” (ABRÃO, 2003, p. 1). Ou seja, não há uma adaptação das leis para as novas tecnologias que surgiram após 1998 - a saber, as redes $\mathrm{P} 2 \mathrm{P}$, os fóruns de discussão, os blogues, os microblogues, os sites de redes sociais ${ }^{\text {iv }}$. Sendo assim, a reprodução e a distribuição do conteúdo do webjornal configuram-se como uma infração do direito patrimonial da empresa jornalística.

Ao mesmo tempo em que se constitui em infração, a apropriação do conteúdo pode realizar uma circulação maior e até pode fazer com que alcance uma maior audiência para a página original da publicação. Se a cópia do conteúdo estiver vinculada com o link para o conteúdo original, o usuário pode se interessar e visitar a página do site - o que também mantém o direito moral do criador.

Uma alternativa para o impasse que se firmou é a adoção das licenças livres pelos produtores de conteúdo. As licenças são autorizações que têm a exigência básica da 
Estudos em Jornalismo e Mídia - Vol. 9 N I - Janeiro a Junho de 2012

atribuição do crédito ao autor, ou origem, e, assim, permitem que o conteúdo seja copiado. Ao utilizá-las, o autor concede a distribuição da obra, aderindo a um acordo de determinadas liberdades, ou a um sistema no qual ele escolhe quais liberdades autoriza. De surgimento relativamente recente, as licenças têm alcançado uma grande popularidade e derivam de um contexto maior - a cultura livre.

\section{Surgimento dos direitos autorais e da cultura livre}

Os direitos autorais começaram a ser regulados há cerca de três séculos, mas suas origens remontam ao século XV. Até a Idade Média, os processos de reprodução das obras artísticas, literárias e científicas eram realizados de forma manual e rudimentar, o que dificultava a divulgação de ideias (VIANNA, 2006, p. 935). Em torno de 1450, com o surgimento da máquina de imprimir com tipos móveis (BURKE, 2003) passou-se a se pensar nos direitos desses textos, devido à facilitação da reprodução textual. Quem tinha os meios de reprodução, recebia dos governantes o direito exclusivo de comercializar os escritos. Os reis ingleses Felipe e Maria Tudor são considerados os primeiros a concederem um monopólio para livreiros, em 1557, conforme conta Abrão (2001, p. 27). A esse privilégio de produzir e comercializar os livros, foi dado o nome de direito de cópia (copyright, em inglês).

Os livreiros mantiveram seu domínio até 1664, quando expirou o limite de exploração garantido pelo Licensing Act, um decreto que lhes dava o poder de combater os livros falsificados - que não tinham autorização. Em 1710, a Rainha Ana aprovou o Statute of Anne, considerada a primeira lei de direitos autorais da história, pois reconhecia a propriedade das obras como sendo dos autores, e não dos livreiros. Além de reconhecer o direito patrimonial dos autores, a lei também estabeleceu limites para o direito de cópia (copyright) do livreiro - cada livro poderia ser explorado por 14 anos, com direito a uma renovação por mais 14 anos, se o autor estivesse vivo. Para os livros anteriores à lei, foi estabelecido o prazo de 21 anos. Após esse tempo, o livro poderia ser publicado por qualquer pessoa, passando ao domínio público, um conceito novo para a época. Esse 
Estudos em Jornalismo e Mídia - Vol. 9 N I - Janeiro a Junho de 2012

sistema de direito autoral inglês originou o copyright dos países anglo-saxões - dentre eles, o dos Estados Unidos, cuja primeira lei data de 1790.

Os direitos autorais do Brasil e dos demais países latino-americanos deriva do sistema "droit d'auteur", surgido na França pouco depois da Revolução Francesa, e pouco depois do copyright:

Em julho de 1793, com a classe dos artistas contemplada com algumas normas de proteção, um Decreto-lei do governo francês regulou, pela primeira vez, os direitos de propriedade dos autores de escritos de todos os gêneros, do compositor de música, dos pintores e dos desenhistas. (ABRÃO, 2001, p. 31)

O direito do autor francês se preocupava não só com o direito de cópia da obra - do copyright inglês -, mas também com os direitos morais do autor.

Quase um século depois, os dois tipos de sistema de direitos autorais foram debatidos na Convenção da União de Berna, em 1886. A Convenção foi uma tentativa dos países de regular uma proteção mínima para o direito autoral internacional. A normatização ficaria a cargo das legislações internas de acordo com os costumes de cada país. Entretanto, dentre as determinações, ficou estabelecido "princípios de proteção mínima", como o prazo mínimo de proteção a obra (vida do autor, mais cinquenta anos após morte). Em outras revisões do texto, o prazo seria aumentado para setenta anos, como é hoje no mundo e no Brasil.

Os Estados Unidos na época não assinaram a Convenção e mantiveram o sistema de copyright, que sofreu muitas mudanças ao longo dos anos. Houve um enrijecimento da lei de copyright, principalmente no prazo do domínio público norte-americano que foi estendido em sucessivos processos de reformulação da lei. Lessig (2005) faz um apanhado histórico das modificações operadas na lei estadunidense:

Nos primeiros 100 anos de República, o contrato de copyright foi modificado uma vez. Em 1831, o prazo máximo de decadência do contrato foi ampliado 28 anos para 42 , ao se aumentar o contrato inicial de 14 para 28 anos. Nos 50 anos seguintes de República, o contrato foi ampliado mais uma vez. Em 1909, o Congresso estendeu o tempo de renovação de 14 para 28 anos, estabelecendo um contrato máximo de 56 anos. Então, no começo de 1962, o Congresso deu início a uma prática 
Estudos em Jornalismo e Mídia - Vol. 9 N I - Janeiro a Junho de 2012

que passou a definir exclusivamente a lei de copyright. O Congresso ampliou os contratos de copyright existentes 11 vezes nos últimos 40 anos; por duas vezes nesses 40 anos, ampliou os contratos de futuros copyrights. Inicialmente, as expansões para os contratos de copyrights existentes eram curtas - um ou dois anos apenas. Em 1976, o Congresso prolongou todos os copyrights existentes por 19 anos. E, em 1998, no Ato Sonny Bono de Extensão de Contrato de Copyright, o Congresso prolongou os contratos de copyright existentes e futuros por 20 anos. O objetivo dessas ampliações era apenas anular ou retardar a passagem das obras para o domínio público. (LESSIG, 2005, p. 147)

Para Lessig (2005), deve haver uma adequação na lei de copyright, e não sua extinção, de acordo com as inovações tecnológicas que facilitaram a reprodução e distribuição dos bens culturais. Lessig defende que a cultura deve voltar a ser livre, não livre no sentido de coisas materiais gratuitas, mas livre no sentido de liberdade de expressão, de mercados, de comércios e de iniciativas. O termo "livre" significa que os bens culturais são isentos das restrições impostas pela legislação copyright, que possui como lema os dizeres "todos os direitos reservados". Reservados, pois a cópia, a reprodução e outros direitos patrimoniais são exclusivos dos seus respectivos detentores. $\mathrm{Na}$ cultura livre, apenas alguns direitos são reservados, à escolha do criador da obra cultural para que ela seja copiada e modificada por outras pessoas.

Uma cultura livre apóia e protege criadores e inovadores. Faz isso diretamente, garantindo direitos de propriedade intelectual. Mas também faz isso indiretamente, limitando o alcance desses direitos, para garantir que os criadores e inovadores subseqüentes permaneçam tão livres quanto possível do controle do passado. Uma cultura livre não é uma cultura sem propriedade, da mesma forma que um mercado livre não é um mercado onde tudo é grátis. O oposto de uma cultura livre é uma "cultura da permissão", na qual os criadores só criam com a permissão dos poderosos ou dos criadores do passado. (LESSIG, 2005, p. 26)

A defesa por uma cultura livre tem suas bases no copyleft e no software livre, como constatado por Schwingel (2006, online), pois se refere a "movimentos que extrapolem os preceitos e idéias surgidas a partir da relativização dos direitos de propriedade intelectual e do desenvolvimento colaborativo". A seguir, será dado um enfoque maior na relativização do direito autoral ocasionada pelo copyleft. 
Estudos em Jornalismo e Mídia - Vol. 9 N I - Janeiro a Junho de 2012

ISSNe 1984-6924

DOI I0.5007//984-6924.20I2v9nIpI96

\section{Copyleft}

Copyleft é uma palavra criada a partir da inversão do termo copyright, e que quer dizer "deixar copiar". Ao contrário do que parece, ela não designa outro conjunto de direitos ou outra licença. Determinadas licenças de uso são denominadas copyleft por permitirem a distribuição dos bens culturais.

O copyleft se origina em meados dos anos 1980 a partir do surgimento do conceito de software livre. Em 1983, o pesquisador estadunidense do Massachusetts Institute of Technology (MIT), Richard Stallman, criou o projeto GNU (sigla metalinguística para GNU is Not Unix) com o objetivo de "produzir um sistema operacional livre que pudesse fazer o mesmo que o sistema Unix" (SILVEIRA, 2004, p. 18). Stallman queria que todos tivessem acesso ao software e pudessem adaptá-lo conforme as suas necessidades ou gostos. O projeto GNU tinha o seu código fonte - que contém todas as linhas de instruções do programa - aberto para estudo e modificações, ao contrário dos sistemas operacionais Unix, que tiveram seus códigos-fonte fechados e apropriados comercialmente por uma empresa de telecomunicações, a AT\&T (American Telephone and Telegraph).

Stallman definiu quatro liberdades fundamentais para um software ser considerado livre:

Liberdade 0: A liberdade de executar o programa, para qualquer propósito;

Liberdade 1: A liberdade de estudar como o programa funciona, e adaptálo para as suas necessidades (Acesso ao código fonte é uma pré-condição para isso.);

Liberdade 2: A liberdade de redistribuir cópias de modo que você possa ajudar ao seu próximo;

Liberdade 3: A liberdade de aperfeiçoar o programa, e liberar os seus aperfeiçoamentos, de modo que toda a comunidade se beneficie (Acesso ao código-fonte é uma pré-condição para isso. $)^{\mathrm{v}}$

(STALLMAN, 2002, p. 43).

As liberdades poderiam ser asseguradas ao registrar o programa como domínio público. Entretanto, isso poderia permitir que outras pessoas convertessem o programa para um software proprietário. O fechamento do software negaria a outras pessoas a 
Estudos em Jornalismo e Mídia - Vol. 9 N I - Janeiro a Junho de 2012

possibilidade de livre acesso, modificação e de redistribuição - uma consequência que limitaria o desenvolvimento colaborativo. A fim de evitar a apropriação do software construído conjuntamente, Stallman cunhou o conceito de copyleft, que se utiliza do copyright, através de instrumentos legais, para assegurar as determinadas liberdades.

As condições e as exigências para o uso do software são adicionadas por meio de uma licença jurídica. Para o sistema GNU, foi criada em 1989 a primeira licença copyleft a GNU GPL (GNU General Public License ou Licença Pública Geral GNU). Conforme apontam Lima e Santini (2006), além de permitir a livre distribuição, essa licença permite que as cópias modificadas sejam comercializadas, desde que não infrinjam alguma das quatro liberdades do software livre. É possível cobrar pelas cópias do software, mas não é permitida a proibição de futuras modificações que possam contribuir para o aprimoramento do programa. É uma distinção importante, uma vez que software livre pode não ser grátis. O livre quer dizer basicamente que a utilização, a modificação e a distribuição são gratuitas. O programa pode ser utilizado comercialmente, desde que seu código-fonte seja aberto.

No jornalismo, alguns portais brasileiros que denominam seu conteúdo como copyleft são a Agência Carta Maior vi e o Jornal Le Monde Diplomatique Brasil ${ }^{\mathrm{vii}}$. A editora do site do Le Monde, Maíra Kubik Mano, disse que o jornal se pauta pelo princípio do conhecimento partilhado,

que visa estimular a ampla circulação de idéias e produtos culturais. A leitura e reprodução dos textos é livre, no caso de publicações nãocomerciais. A única exceção são os artigos da edição mensal mais recente. A citação da fonte é sempre bem-vinda (MANO, 2010, online).

A Agência Carta Maior adota o conceito desde 2001, e todas as notícias veiculadas no portal possuem a palavra "Copyleft" ao lado da editoria e da data de publicação.

Silveira (2007) enxerga o ciberespaço como um ambiente propício para a circulação de informações e bens culturais:

Com o crescimento da digitalização e da Internet, cresceu também as possibilidades de compartilhar bens culturais e informações como em nenhum outro período da história. Era possível criar um domínio público global que acompanhasse o ciberespaço. O ciberespaço passou a ser visto com o local ideal para os commons. (SILVEIRA, 2007, p. 6) 
Estudos em Jornalismo e Mídia - Vol. 9 N I - Janeiro a Junho de 2012

Segundo Silveira (2007), os commons são recursos imateriais, tanto produções quanto espaços, que são comuns a todos os participantes de coletivos ou de comunidades. De acordo com Silveira (2007, p.7), através da ampliação dos commons, Lawrence Lessig vê uma reconstrução do domínio público, "pois sem ele, não teremos material para a criatividade e para a inovação”. Inspirado em Richard Stallman e na GNU GPL, Lessig (2005) idealizou o projeto Creative Commons, que disponibiliza um conjunto de licenças para a utilização em qualquer tipo de conteúdo - e assim torna acessíveis bens digitais, sem entraves jurídicos.

\section{Creative Commons}

O conjunto de licenças Creative Commons pode ser aplicado a qualquer tipo de obra: música, audiovisual, fotografia, software, blogues, jornais ou qualquer outra passível de proteção pelos direitos autorais. O sistema de licenciamento jurídico foi desenvolvido para pessoas ou entidades que queiram disponibilizar suas criações para cópia, distribuição ou modificação. Lemos, R. (2005, p. 83) ressalta que "até o surgimento da internet, da tecnologia digital e de um modelo jurídico como o Creative Commons, não havia meios para que esses autores pudessem indicar à sociedade que eles simplesmente não se importam com a divulgação de suas obras".

Iniciado em 2001, o desenvolvimento do sistema foi idealizado por Lawrence Lessig, professor de Direito da Universidade de Stanford, EUA. Com o projeto Creative Commons - uma organização sem fins lucrativos -, Lessig tem por objetivo:

construir uma camada de conteúdo regulada por uma camada plausível de legislação do copyright, na qual outros possam se basear. A escolha voluntária de indivíduos e criadores tornará o conteúdo disponível. E esse conteúdo nos permitirá reconstruir um domínio público. (LESSIG, 2005, p. 276)

A partir dos Estados Unidos, o projeto logo se espalhou por vários países através da web. Por terem sido redigidas para o copyright estadunidense, as licenças tiveram que ser 
Estudos em Jornalismo e Mídia - Vol. 9 N I - Janeiro a Junho de 2012

ISSNe 1984-6924

adaptadas aos países que aderiram ao projeto. Hoje, os termos estão completamente traduzidos e adaptados para as diferentes jurisdições de 53 nações ${ }^{\text {vii }}$ - entre elas o Brasil.

Em dezembro de 2002, o projeto lançou a primeira versão do sistema de licenças, a 1.0. Desde então, três revisões já foram feitas - em 2004, 2005 e 2007. No Brasil, o Creative Commons foi adaptado pela Escola de Direito da Fundação Getúlio Vargas do Rio de Janeiro desde maio de $2004^{\text {ix }}$. A versão 3.0, a mais recente do sistema, foi lançada em São Paulo no dia 29 de janeiro de $2010^{x}$.

A escolha das autorizações por parte dos produtores ocorre através do site do projeto $^{\mathrm{xi}}$. Nele, é possível encontrar obras já licenciadas, fazer doações ao projeto, e escolher uma das licenças. Para escolher a licença, é preciso preencher um formulário com as condições de uso, modificação e distribuição permitidas aos consumidores. $\mathrm{Na}$ sequência, são vistas com mais detalhes cada licença CC.

\section{Licenças do Creative Commons}

Cada licença é representada por um respectivo selo, tendo por padrão apenas o símbolo do Creative Commons, como mostra a seguinte tabela explicativa com os seis modelos:

Tabela 1

Selos e as seis licenças Creative Commons, de acordo com Vercelli (2009)

\begin{tabular}{l|l|l}
\hline Selo & Nome & Significado \\
\hline CC & Atribuição (Attribution / by) & $\begin{array}{l}\text { Permite que outros copiem, distribuam, } \\
\text { remixem, adaptem ou criem obras } \\
\text { derivadas, mesmo que para uso com fins } \\
\text { comerciais, contanto que seja dado crédito } \\
\text { pela criação original. É a licença menos } \\
\text { restritiva de todas as oferecidas, em termos } \\
\text { de quais usos outras pessoas podem fazer } \\
\text { da obra. }\end{array}$ \\
\hline
\end{tabular}




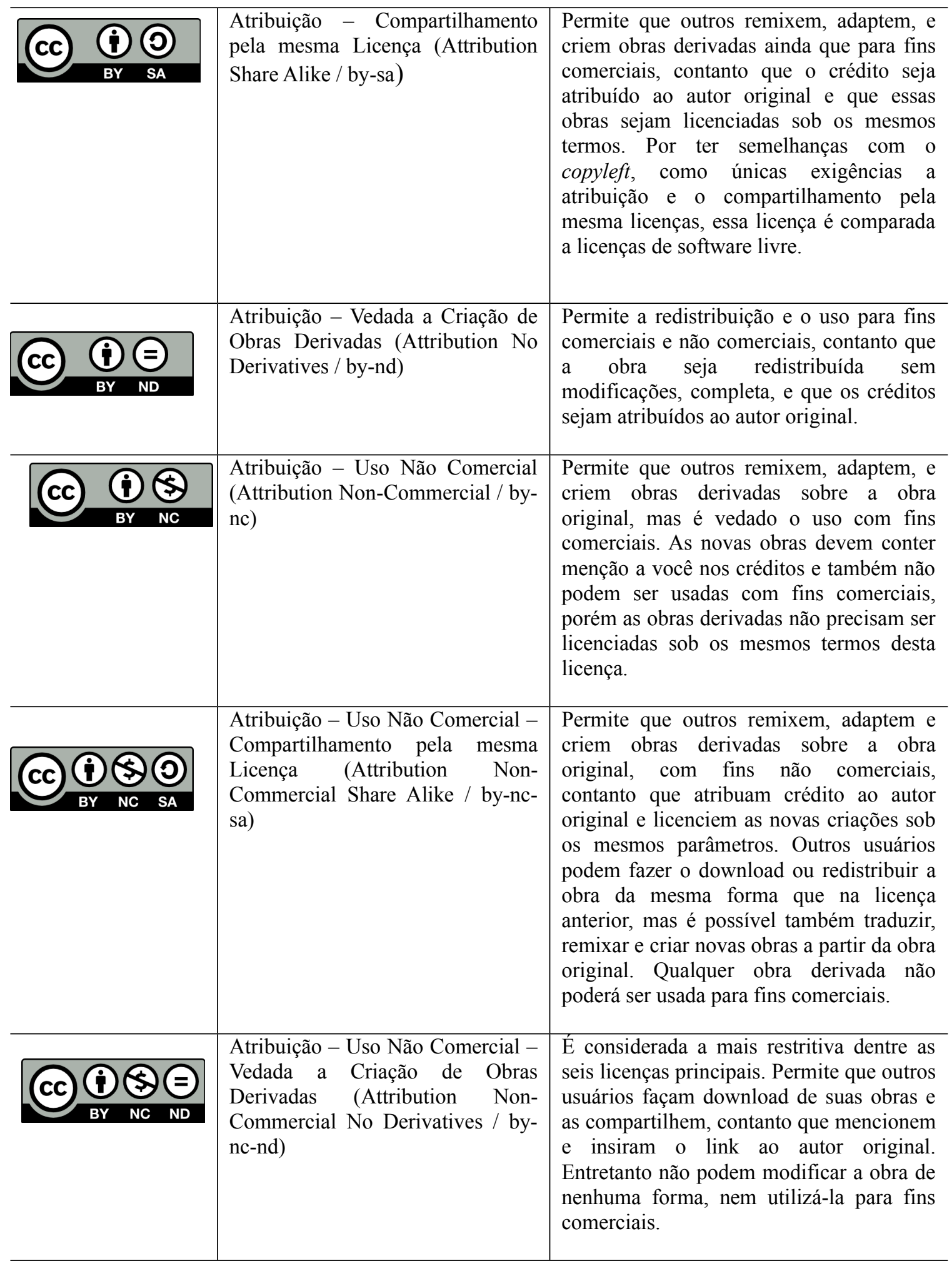


Normalmente, os selos são mostrados junto às obras que possuem o seu licenciamento. Eles permitem visualizar rapidamente qual licença específica se está utilizando em cada obra (VERCELLI, 2009). Outro tipo de selo é o que aparece apenas o símbolo do Creative Commons com o lema da entidade - "alguns direitos reservados" (some rights reserved, em inglês).

Um exemplo recente da aplicação das licenças no jornalismo é a adoção por parte do site da Revista Wired italianaxii . Desde o dia 6 de outubro de 2010, todas as notícias do site exibem o selo de Atribuição - Uso Não Comercial - Vedada a Criação de Obras Derivadas (Attribution Non-Commercial No Derivatives / by-nc-nd). Isso quer dizer que a notícia pode ser copiada e republicada - desde que seja atribuída a autoria da Revista -, que o uso não renda lucro ao copiador e que este não modifique o conteúdo.

Outros sites jornalísticos já adotaram as licenças Creative Commons, como o Jornalistas da $W_{e} b^{\text {xiii }}$ e o blogue do jornalista Tiago Dória ${ }^{\text {xiv }}$, fato que torna livre a utilização, modificação e distribuição não comercial do conteúdo. Já em julho de $2007^{\mathrm{xv}}$, o jornal espanhol 20 minutos licenciou todo seu conteúdo próprio. A rede de televisão árabe Al Jazeera colocou sua produção audiovisual sob o sistema desde janeiro de $2009^{\mathrm{xvi}}$. Muitos portais com seções de jornalismo colaborativo já mostram em suas páginas que as notícias podem ser copiadas e coladas com a atribuição da origem - por exemplo, a seção "Minha Notícia” do portal $\operatorname{Ig}^{\mathrm{xvii}}$.

\section{Considerações finais}

As licenças Creative Commons servem como uma forma de flexibilização dos direitos autorais de produtores de conteúdo, que permitem a reprodução e a circulação livre, mediante a mínima citação da autoria. Para circular sua produção na rede, o autor pode abrir mão de algumas proteções das atuais leis de direito autoral adotando as licenças. A mínima exigência de atribuição pode trazer um retorno de audiência e autoridade, através do linkamento da rede, para o produtor. 
Estudos em Jornalismo e Mídia - Vol. 9 № I - Janeiro a Junho de 2012

A circulação é uma das quatro etapas do processo jornalístico, conforme Gonçalves e Palacios (2007): apuração, produção, circulação e consumo de informações. A digitalização das notícias permite uma facilidade de circulação maior em relação ao meio físico, no processo de copia e distribuição através da rede, como observa Lemos (2005, p. 31): "Várias formas de expressão protegidas podem ser transformadas para o formato digital, tais como textos, vídeos e sons, e a internet permite, de modo muito fácil, a circulação desses bens intelectuais". Todavia, a Lei dos Direitos Autorais vigente não contempla as possibilidades de circulação e ou publicação na internet.

Uma forma de relativizar essa situação seria a adoção, por parte das empresas que detêm os direitos patrimoniais de seus jornalistas, de alguma das licenças copyleft. Muitos dos produtores de conteúdo optam pelo licenciamento, visando a uma melhor circulação de suas criações, facilitando o acesso a elas e assim alcançando maiores audiências.

As licenças Creative Commons podem incentivar a participação e a colaboração do público em todas as etapas jornalísticas - desde a apuração, através de canais de colaboração, até a circulação, com o compartilhamento das notícias nos sites de redes sociais. Além de engajarem o crescente público usuário da internet, ainda propiciam o exercício legal do provimento ao acesso de informação, tão necessário para o desenvolvimento da cidadania na democracia moderna.

\section{Referências bibliográficas}

ABRÃO, Eliane Yachouh. Direitos de autor e direitos conexos. 1 1aed., São Paulo, Editora do Brasil, 2002.

Eliane Yachouh. A internet e sua inserção no sistema dos direitos autorais. Revista do Advogado,

São Paulo, ano 23, n. 69, p. 78, maio 2003. Disponível em: < http://www2.uol.com.br/direitoautoral/artigo211003 a.htm > Acesso em: 25 de nov. 2010.

BRASIL. Decreto-lei $\mathrm{n}^{\mathrm{o}}$ 5.452, de $1^{\circ}$ de maio de 1943. Disponível em: < http://www.planalto.gov.br/ccivil/Decreto-Lei/Del5452.htm > Acesso em: 25 de nov. de 2010.

BRASIL. Lei $\mathrm{n}^{\mathrm{o}}$ 9.610, de 19 de fevereiro de 1998. Disponível em: < http://www.planalto.gov.br/ccivil/leis/L9610.htm > Acesso em: 25 de nov. de 2010.

BURKE, Peter. Uma história social do conhecimento. Rio de Janeiro: Jorge Zahar, 2003. 
Estudos em Jornalismo e Mídia - Vol. 9 N ${ }^{\circ}$ I - Janeiro a Junho de 2012

CASTRO, Lincoln Antônio de . Noções sobre Direito Autoral. Revista de Direito do Ministério Público, Rio de Janeiro, n. 13, p. 207-214, 2001. Disponível em: < http://www.estacio.br/graduacao/direito/publicacoes/dir diraut.asp $>$ Acesso em: 25 de nov. 2010.

GONÇALVES, E. M. ; PALACIOS, Marcos . Um modelo híbrido de pesquisa: a metodologia aplicada ao GJOL. In: Machado, Marcia B., Lago, Claudia. (Org.). Metodologia de pesquisa em jornalismo. 1a ed. Petropolis: Vozes, 2007, v. 1, p. 199-222. Disponível em: < http://www.facom.ufba.br/jol/pdf/2007_palacios\%20_elias_metodologia_GJOL.pdf $>$ Acesso em: 25 de nov. 2010.

LEMOS, Ronaldo . Direito, Tecnologia e Cultura. Rio de Janeiro: Editora FGV, 2005. 211 p. Disponível em:

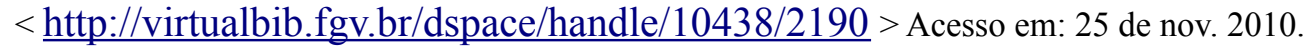

, Ronaldo ; Branco, Sérgio . Copyleft, Software Livre e Creative Commons: A Nova Feição dos Direitos Autorais e as Obras Colaborativas. Revista de Direito Administrativo, v. 243, p. 180-210, 2006. Disponível em: < http://virtualbib.fgv.br/dspace/handle/10438/2796 > Acesso em: 25 de nov. 2010.

LESSIG, Lawrence. Cultura Livre: Como a grande mídia usa a tecnologia e a lei para barrar a criação cultural e controlar a criatividade. São Paulo, Trama, 2005. Disponível em: < http://www.scribd.com/doc/5266831/Lawrence-Lessig-Cultura-Livre > Acesso em: 25 de nov. 2010 .

LIMA, Clóvis Ricardo Montenegro de ; SANTINI, Rose Marie . Copyleft e licenças criativas de uso de informação na sociedade da informação. Ciência da Informação, v. 37, p. 121-128, 2008. Disponível em: < http://revista.ibict.br/index.php/ciinf/article/viewArticle/924 > Acesso em: 25 de nov. 2010.

MANO, Maíra Kubík. De cara nova. 2010. Disponível em: < http://diplomatique.uol.com.br/acervo.php?id=2277 > Acesso em: 25 de nov. 2010.

PARANAGUÁ, Pedro; BRANCO, S. . Direitos Autorais. 1. ed. Rio de Janeiro: FGV Editora, 2009. v. 1. 144 p. Disponível em: < http://virtualbib.fgv.br/dspace/handle/10438/2756 > Acesso em: 25 de nov. 2010 .

SCHWINGEL, Carla. O Copyleft e o Desenvolvimento Colaborativo como Bases da Cultura Livre. Razón y Palabra, v. actual, p. 53, 2006. Disponível em: < http://www.www.razonypalabra.org.mx/anteriores/n53/cshwingel.html > Acesso em: 25 de nov. 2010 .

SILVEIRA, Sérgio Amadeu . Software Livre: a luta pela liberdade do conhecimento. São Paulo: Editora Perseu Abramo, 2004. Disponível em: $<$ http://www.fpa.org.br/o-quefazemos/editora/livros/software-livre-luta-pela-liberdade-do-conhecimento $>$ Acesso em: 25 de nov. 2010.

, Sérgio Amadeu . O conceito de commons na cibercultura. In: XXX Congresso Brasileiro de Ciências da Comunicação, 2007, Santos. Anais do XXX Congresso Brasileiro de Ciências da Comunicação, 2007. São Paulo : Editora Intercom, 2007. Disponível em: < 
http://revistas.univerciencia.org/index.php/libero/article/viewFile/5397/4914 > Acesso em: 25 de nov. 2010.

STALLMAN, Richard. Free software, free society: selected essays of Richard Stallman. Boston: GNU Press, 2002. Disponível em: < http://shop.fsf.org/product/free-software-free-society/ > Acesso em: 25 de nov. 2010.

VERCELLI, Ariel. Repensando los bienes intelectuales comunes: análisis sociotécnico sobre el proceso de coconstrucción entre las regulaciones de derecho de autor y derecho de copia y las tecnologías digitales para su gestión. Buenos Aires, 2009. Disponível em: $<$ http://www.arielvercelli.org/libros/ $>$ Acesso em: 25 de nov. 2010.

VIANNA, Túlio Lima . A ideologia da propriedade intelectual: a inconstitucionalidade da tutela penal dos direitos patrimoniais de autor. Anuario de Derecho Constitucional Latinoamericano, v. 12, II, p. 933-948, 2006. Disponível em: $<$ http://www.tuliovianna.org/index.php > Acesso em: 25 de nov. 2010. 
${ }^{\mathrm{i}}$ Redes em que os computadores se conectam entre si com um computador administrador da rede, possibilitando que todos compartilhem arquivos.

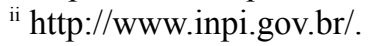

iii " $\S 1^{\circ}$ - Entende-se como jornalista o trabalhador intelectual cuja função se estende desde a busca de informações até a redação de notícias e artigos e a organização, orientação e direção desse trabalho.”.

${ }^{\text {iv }}$ O Ministério da Cultura (MINC) abriu uma consulta pública para modernização da Lei do Direito Autoral este ano. De 14 de junho a 31 de agosto de 2010, foram recebidas 8 mil 431 sugestões de mudanças. Mais informações podem ser conferidas no site da consulta: http://www.cultura.gov.br/consultadireitoautoral/.

vTradução do autor para: "Freedom 0: The freedom to run the program, for any purpose.;

Freedom 1: The freedom to study how the program works, and adapt it to your needs. (Access to the source code is a precondition for this.);

Freedom 2: The freedom to redistribute copies so you can help your neighbor.;

Freedom 3: The freedom to improve the program, and release your improvements to the public, so that the whole community benefits. (Access to the source code is a precondition for this.)" (STALLMAN, 2002, p. 43).

${ }^{\mathrm{vi}}$ http://www.cartamaior.com.br/

vii http://diplomatique.uol.com.br/

viii A lista completa dos países pode ser vista em: http://creativecommons.org/international/.

ix $\mathrm{http}$ ://informatica.terra.com.br/interna/0,,OI308489-EI553,00.html.

${ }^{x}$ http://idgnow.uol.com.br/blog/campus-party/2010/01/19/lessig-lanca-versao-brasileira-do-creative-commons-3-0-nacampus-party-2010/.

${ }^{\text {xi } h t t p: / / c r e a t i v e c o m m o n s . o r g / . ~}$

xii http://mag.wired.it/rivista/storie/se-il-web-e-morto-il-copyright-cos-e.html.

xiii http://www.jornalistasdaweb.com.br/.

xiv http://www.tiagodoria.ig.com.br/.

${ }^{x v}$ http://blogs.20minutos.es/retiario/2007/07/19/el-futuro-la-prensa-es-abierto/.

${ }^{x v i}$ http://www.jornalistasdaweb.com.br/index.php?pag=displayConteudo\&idConteudo=3733.

${ }^{x v i i}$ http://minhanoticia.ig.com.br/creative_commons/. 